\title{
Experimental Study on Seismic Behavior of RC Frame Beam Column Joints
}

\author{
Shen Zhaoyi ${ }^{1}$, Gong Maosheng ${ }^{1,}$, Zuo Zhanxuan ${ }^{2}$, Zhang Hao ${ }^{1}$ \\ ${ }^{1}$ Institute of Engineering Mechanics, China Earthquake Administration, Harbin, China \\ ${ }^{2}$ Key Laboratory of Earthquake Engineering and Engineering Vibration, Institute of Engineering Mechanics, China Earthquake Administration, \\ Harbin, China
}

Email address:

420442114@qq.com (Shen Zhaoyi), gmshiem@163.com (Gong Maosheng), zuozhanxuan@sina.com (Zuo Zhanxuan), 351110412@qq.com (Zhang Hao)

${ }^{*}$ Corresponding author

\section{To cite this article:}

Shen Zhaoyi, Gong Maosheng, Zuo Zhanxuan, Zhang Hao. Experimental Study on Seismic Behavior of RC Frame Beam Column Joints. Science Discovery. Vol. 9, No. 4, 2021, pp. 184-189. doi: 10.11648/j.sd.20210904.19

Received: April 30, 2021; Accepted: June 10, 2021; Published: June 22, 2021

\begin{abstract}
Strong columns and weak beams" and "strong joints and weak members" are important concepts in the design of reinforced concrete ductile frame structures. However, many earthquake damages show that a large number of reinforced concrete frame structures still do not guarantee the realization of the above seismic concepts. In order to solve this problem, this paper designs and manufactures a beam column joint with plate, which includes the bottom column base and the moment increasing coefficient of the column end is 1.2. Through the quasi-static reciprocating loading test, the influence of the bearing capacity, ultimate deformation, stiffness degradation and hysteretic energy consumption of the specimen is investigated. The test results show that when the moment increasing factor at the end of the column is 1.2 , the failure order of the specimen is bottom column base beam slab bottom column base, the plastic hinge occurs at the bottom of the column, and the position of the column in the beam column joint is not damaged; According to the seismic code, the overall failure mode of the beam column joints with slab and infilled wall at the bottom column base can be "strong column and weak beam" and "strong joint and weak member" under the action of reciprocating quasi-static loading.
\end{abstract}

Keywords: Strong Column and Weak Beam, Slab, Beam-column Joint, Pseudo-static Test

\section{RC框架结构梁柱节点抗震性能试验研究}

\author{
沈召义 ${ }^{1}$, 公茂盛 ${ }^{*}$, 左占宣 ${ }^{2}$, 张浩 $^{1}$ \\ 1 中国地震局工程力学研究所, 哈尔滨, 中国 \\ ${ }^{2}$ 中国地震局工程力学研究所中国地震局地震工程与工程振动重点实验室, 哈尔滨, 中国
}

\section{邮箱}

420442114@qq.com（沈召义）, gmshiem@163.com（公茂盛）, zuozhanxuan@sina.com（左占宣）, 351110412@qq.com（张浩）

\begin{abstract}
摘要：“强柱弱梁”和“强节点弱构件”是钢筋混凝土延性框架结构设计中的重要概念，但多次地震震害显示，大量钢筋 混凝土框架结构仍未保证以上抗震概念的实现。针对此问题, 本文设计制作了一个包含底层柱脚的柱端弯矩增大系数 为 1.2 的梁柱中柱节点带板试件, 通过拟静力往复加载试验, 考察试件的承载力、极限变形、刚度退化以及滞回耗能等 方面抗震性能的影响。试验结果表明, 当柱端弯矩增大系数为 1.2 时, 试件破坏顺序为底层柱脚-梁板-底层柱脚, 结构 在柱底产生了塑性铰, 梁柱节点中柱的位置始终未发生破坏; 按照抗震规范设计的底层柱脚有板无填充墙梁柱节点试 件整体在往复拟静力加载的作用下能够出现“强柱弱梁”、“强节点弱构件”的破坏模式。
\end{abstract}


关键词: 强柱弱梁, 现浇楼板, 梁柱节点, 拟静力试验

\section{1. 引言}

为了充分发挥整体框架结构的抗震能力, 避免出现层 倒塌模式等不利的局部型破坏模式, 各国抗震规范均在延 性框架结构的抗震设计中遵循“强柱弱梁”、“强节点弱构件” 等抗震设计理念。在罕遇地震作用下, 结构承载力相对不 足, 需要通过结构的塑性变形弥补。其中, 采用“强柱弱梁 系数”对柱截面受弯承载力需求进行放大, 使与同一节点相 连的柱受弯承载力之和大于梁受弯承载力之和, 是目前各 国抗震规范保证强柱弱梁机制的主要手段。我国现行的《建 筑抗震设计规范》(GB50010-2010)规定, 除一级以外的各 级框架梁柱节点的设计弯矩应满足下式要求 [1]:

$$
\sum M_{c}=\eta_{c} \sum M_{b}
$$

一级的框架结构和 9 度的一级框架结构可不符合上式 要求, 但应符合下式要求:

$$
\sum M_{c} \geq 1.2 \sum M_{\text {bua }}
$$

式中, $\sum M_{c}$ 表示节点上下柱端截面顺时针或反时针方 向组合的弯矩设计值之和, 上下柱端的弯矩设计值, 可以 按照弹性分析分配; $\sum M_{b}$ 表示节点左右梁端截面反时针或 顺时针方向组合的弯矩设计值之和, 一级框架节点左右梁 端均为负弯矩时, 绝对值较小的弯矩应取零; $\sum M_{b u a}$ 表示 节点左右梁端截面反时针或顺时针方向实配的正截面抗 震受弯承载力所对应的弯矩值之和, 根据实配钢筋面积

(计入梁受压筋和相关楼板钢筋) 和材料强度标准值确定。 $\eta_{c}$ 为框架柱端弯矩增大系数, 对于框架结构, 一、二、三、

四级分别取1.7、1.5、1.3、1.2。

国内外学者根据震害调查分析[2-3], 发现框架结构未 实现“强柱弱梁”的屈服机制主要有以下几方面原因：(1)填 充墙等非结构构件的影响; (2)楼板对框架梁的承载力和刚 度增大的影响; (3)框架梁跨度和荷载过大, 使梁截面尺寸 增大, 梁端抗弯承载力增大; (4)梁端超配筋和钢筋实际强 度超强; (5)柱轴压比限值规定偏高, 柱截面尺寸偏小; (6) 柱最小配筋率和最小配䇽率偏小; (7)大震下结构受力状态 与结构弹性受力状态存在差异; (8)梁柱可靠度的差异。蒋 永生等[4]曾做过一组现浇混凝土梁柱节点的对比实验, 指 出带翼缘框架梁由于翼缘内平行于梁肋的钢筋参与受力, 使得节点支座处的实际负向屈服弯矩比无翼缘梁的实测值 提高了 $30 \%$ 左右, 已经超过很多情况下柱端弯矩增大系数 所包含的梁超强富余; Ehsani等[5]人曾进行的一组对比试 验, 对有楼板、无楼板和直交梁的足尺边节点各 6 个试件进 行对比, 在设计试件时考虑了板筋参与梁的受力, 但仍发 现塑性铰在板面以上的柱端形成; French[6]统计了13个中 节点和7个外节点的实验结果后, 发现不考虑楼板作用的计 算承载力比考虑楼板作用的实测承载力分别低 $25 \%$ 和 $17 \%$ 。 唐九如[7]认为, 为了合理考虑楼板影响, 设计框架时若不 计入楼板对框架梁承载力的提高, 则需将柱梁抗弯承载力 比提高至1.4甚至1.6才能使塑性铰出现在梁端。
苏佶智[8]认为梁变形成为层间位移的主要成分, 柱变 形引起的层间位移所占比例次之, 节点剪切变形引起的层 间位移所占比例最小; 刘伯权 [9]通过研究地震倒塌破坏模 式研究, 发现增大结构的坚向荷载可以提高其承载能力及 耗能能力, 但会降低延性及变形能力, 同时, 一定程度地 增大坚向荷载, 有利于强化结构的初始抗侧刚度, 延缓刚 度退化趋势; 王丽萍 $[10]$ 通过试验发现考虑梁轴向约束效 应时, 试件节点抗剪需求增大了1.14-2.22倍, 节点区斜裂 缝宽度较大, 损伤情况更加严重; 初明进[11]认为楼板的 宽度, 厚度和板内配筋以及梁高对梁机制下的承载力有较 大的提高, 其中板宽在大于一定值后影响变得不显著; 只 有楼板宽度和楼板配筋率对悬链线机制下的承载力有显 著影响; 梁内抗震配筋对缩尺试件在两个阶段的抗连续倒 塌承载力影响都不大。吴勇等[12]针对板筋对框架梁的增 强作用这一问题, 对各个国家的规范和国内外的试验资料 进行了分析, 发现楼板的有效宽度并不是板的实际参与宽 度, 而是一种折合宽度。并且建议在梁两侧取6倍的板厚 作为有效翼缘宽度。管民生[13]等利用Pushover分析方法 对带楼板和不带楼板的框架结构分别进行了分析, 空框架 结构基本上呈现梁铰型破坏机制，而带楼板结构几乎都未 能实现强柱弱梁的失效模式。邢国华[14]建立了带楼板和 不带楼板框架结构的有限元模型, 并对结构模型进行 Pushover分析, 通过分析不同水平位移下楼板钢筋应力应 变的变化,给出了有效楼板翼缘宽度的建议取值。杨鹏 [15] 使用ANSYS软件分别对空框架和带楼板框架结构进行了 推覆分析。结果表明, 楼板对结构侧向承载力的提高作用 不明显, 纯框架结构的变形能力要好于带楼板框架结构, 并且可以实现强柱弱梁的失效模式。

现有梁柱节点抗震性能的试验研究通常假设梁、柱反 弯点位于梁跨中或柱一半层高位置, 并在反弯点处截取试 验体。然而在实际震害中, 框架结构底层最容易形成薄弱 层而发生倒塌。由于柱下基础和首层框架梁受弯刚度差异 较大, 首层框架柱的反弯点往往不在柱中央位置。此外, 虽然在整体型梁铰机制中允许底层柱脚进入塑性, 但当轴 压比较大时底层柱脚是否具有足够的塑性变形能力, 或当 “强柱弱梁”机制无法实现时底层框架柱的破坏模式如何, 这些都对框架结构的抗震性能有着重要影响, 因此在梁柱 节点试验中底层柱采用全柱进行试验非常值得研究。

针对以上问题，本文根据《建筑抗震设计规范》 $(\mathrm{GB}$ 50011-2010)设计制作了一个包含底层柱脚的柱端弯矩 增大系数为 1.2 的有板钢筋混凝土框架梁柱节点试验体, 通过拟静力往复加载试验研究现行规范是否能够满足“强 柱弱梁”的破坏模式。

\section{2. 试验概况}

\section{1. 试件设计}

根据《建筑抗震设计规范》(GB 50011-2010)设计 一框架结构。本实验设计了带楼板翼缘的梁柱节点构 
件以及无楼板的梁柱节点构件作为对照组, 以观察楼 板对梁抗负弯矩能力的影响。试验体采用 $1 / 2$ 缩尺模型, 除底层柱保留全长之外, 其他梁、柱均截取到一半的 位置。
根据蒋永生 [4] 以及吴勇 [12]等的研究结果, 楼板 翼缘宽度取6倍的板厚, 即 $360 \mathrm{~mm}$, 梁柱尺寸及配筋见 图1所示。梁柱及底座内纵筋取 HRB 400 三级钢, 䈐筋 与板筋采用HPB300三级钢, 试验中的混凝土等级为 $\mathrm{C} 30$ 。
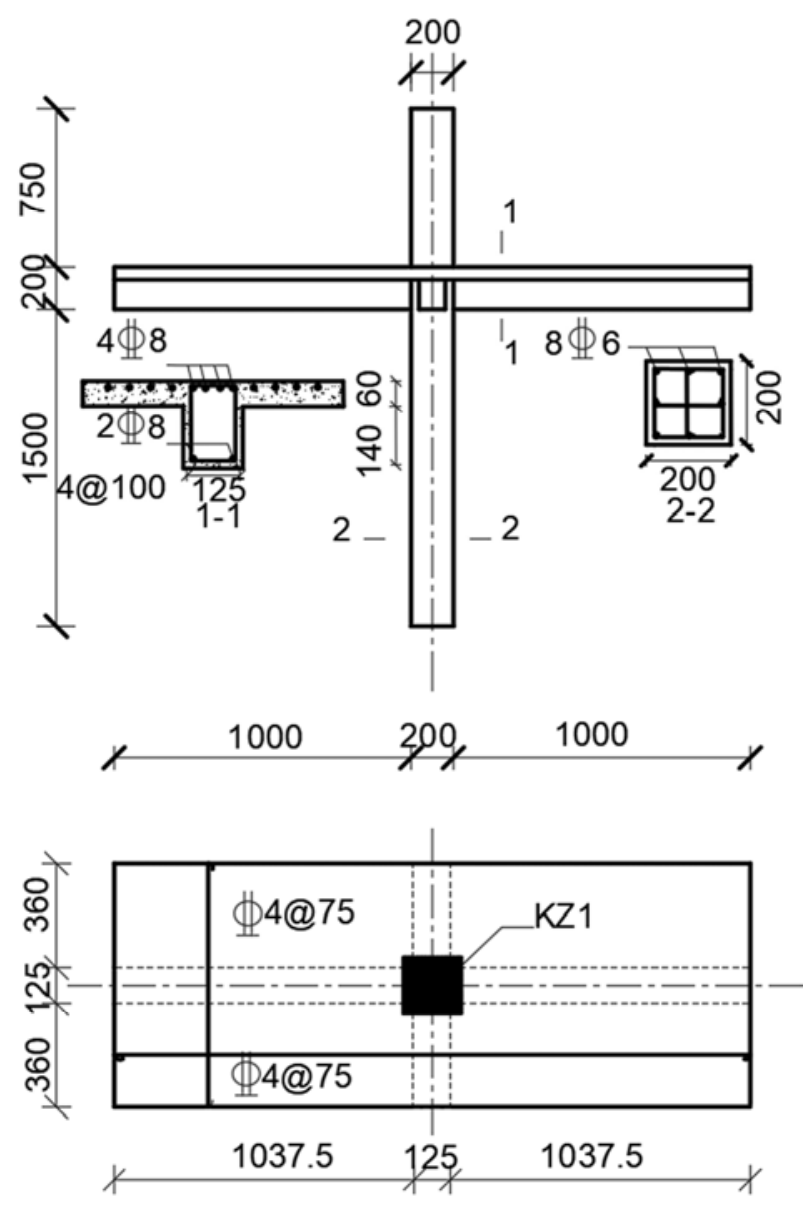

图1 试件梁柱配筋简图(mm)。

\section{2. 材性试验}

本文的试验研究中, 得到钢筋、混凝土的主要材料性 能如表1所示。混凝土的材料力学特性测试通过混凝土立 方体 $(150 \mathrm{~mm} \times 150 \mathrm{~mm} \times 150 \mathrm{~mm})$ 进行抗压强度测试，得
到试验用 $\mathrm{C} 30$ 混凝土立方体抗压强度平均值为 $36.4 \mathrm{MPa}$; 弹性模量为 $34.2 \mathrm{GPa}$ 。4mm箍筋弹性模量为 $281.7 \mathrm{GPa} ; 6 \mathrm{~mm}$ 纵筋弹性模量为 $245.8 \mathrm{GPa}$ 。

表1 材料力学特性。

\begin{tabular}{lll}
\hline 材料 & 力学特性 & 参数 \\
\hline & 峰值抗压强度(MPa) & 34.22 \\
& 峰值应变 & 0.002 \\
$\mathrm{C} 30$ 混凝土 & 极限应变 & 0.0033 \\
& 残余应力 $(\mathrm{MPa})$ & 9.66 \\
& 弹性模量 $(\mathrm{GPa})$ & 34.2 \\
& 立方体抗压强度(MPa) & 36.4 \\
& 屈服强度 $(\mathrm{MPa})$ & 274.1 \\
& 屈服应变 & 0.00172 \\
箅筋 & 极限强度(MPa) & 366.7 \\
& 弹性模量 $(\mathrm{GPa})$ & 281.7 \\
& 屈服强度(MPa) & 544.5 \\
& 屈服应变 & 0.00194 \\
纵筋 & 极限强度(MPa) & 636.1 \\
& 弹性模量 $(\mathrm{GPa})$ & 245.8 \\
\hline
\end{tabular}




\section{3. 试验装置与加载方案}

如图2所示为试验的加载装置, 其水平方向作动器最 大出力为 $500 \mathrm{kN}$, 作动器最大行程为 $\pm 300 \mathrm{~mm}$; 油压千斤 顶其最大出力为 $1000 \mathrm{kN}$, 千斤顶最大行程为 $\pm 250 \mathrm{~mm}$ 。水 平方向作动器内置有力与位移传感器; 千斤顶内置有水平 方向滑轨、球铰及力传感器, 滑轨与球铰能够保证坚向载 荷在试验过程中保持方向坚直向下, 能够根据力传感器的 数值来控制坚向荷载的大小, 使其在加载过程中保持不变。

参考《建筑抗震试验方法规程》(JGJ/T101-2015)[16], 本文试验采用力-位移混合控制加载。首先按力控制模拟 加载, 对试件第一级荷载为 $5 \mathrm{kN}$, 其后每级增加 $5 \mathrm{kN}$ 并循 环一次，一直加载到结构开裂，采用此位移作为试件开裂 位移。之后按位移控制加载, 每个加载等级增加两倍开裂 位移的侧向位移, 并循环两次, 直至试件发生严重破坏, 认为试件达到极限状态，停止加载。

利用液压伺服作动器的内部力传感器和位移传感器 对 RC节点上部柱端作动器作用处进行力与位移的量测, 利用液压千斤顶作动器内部的力传感器对 RC节点柱顶垂 直作用力进行量测。
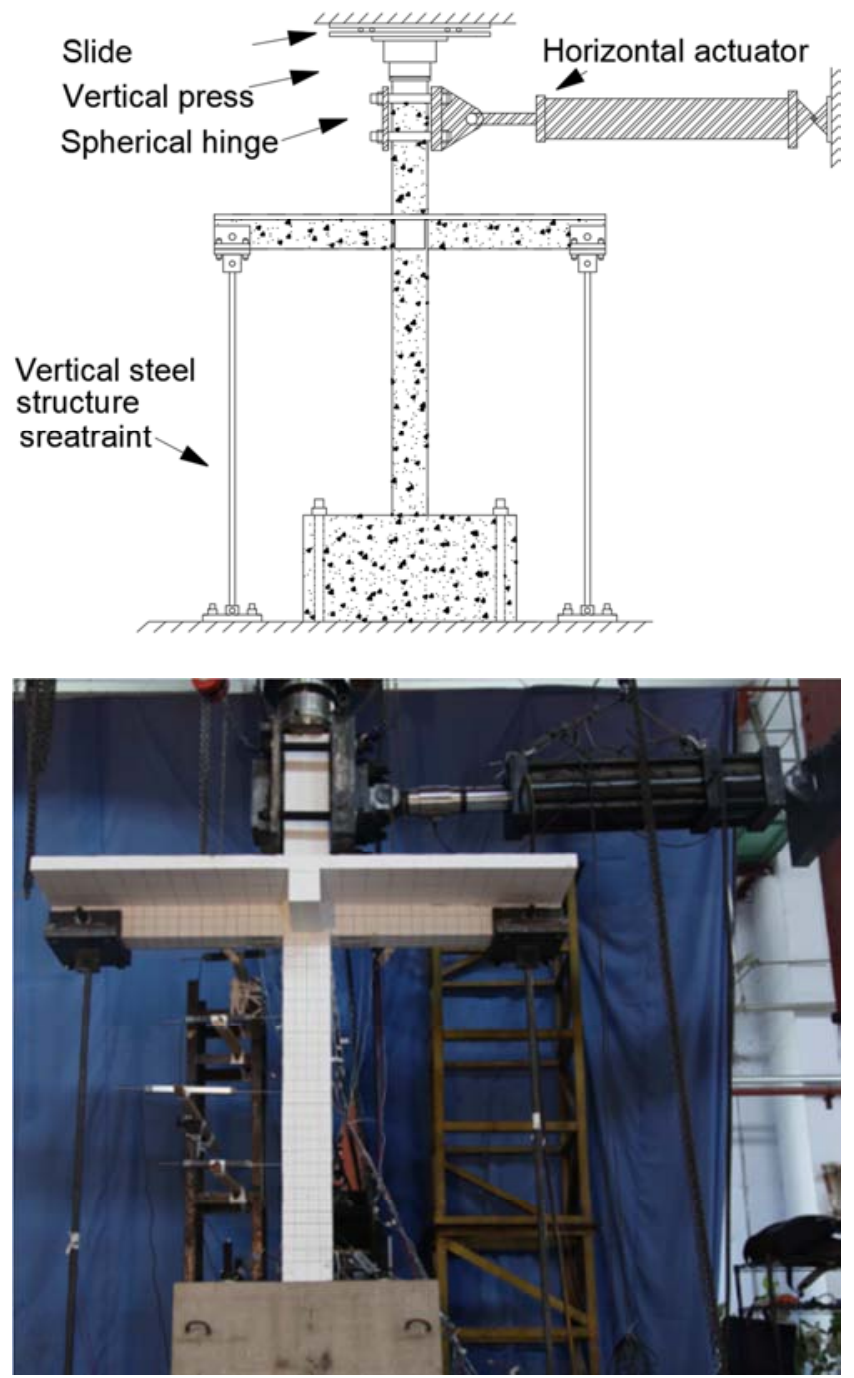

图2 试验加载装置。

\section{3. 试验结果分析}

\section{1. 承载力与极限变形}

本试件的破坏模式为: 在加载初期, 试件底层柱脚先 发生破坏; 随着加载位移的继续增大, 梁板共同产生贯穿 裂缝, 破坏现象为脆性破坏; 在试验加载中期, 底层柱脚 $100 \mathrm{~cm}$ 的范围内逐渐产生抗弯裂缝; 当侧向位移达到 $68 \mathrm{~cm}$ 之后, 底层柱脚混凝土出现大面积剥落现象, 柱底出现塑 性铰, 可明显观察到钢筋屈服, 梁板出现小面积混凝土剥 落; 在试件整体加载的过程中始终未发现梁柱节点中柱的 位置出现水平抗弯裂缝或剪切裂缝。
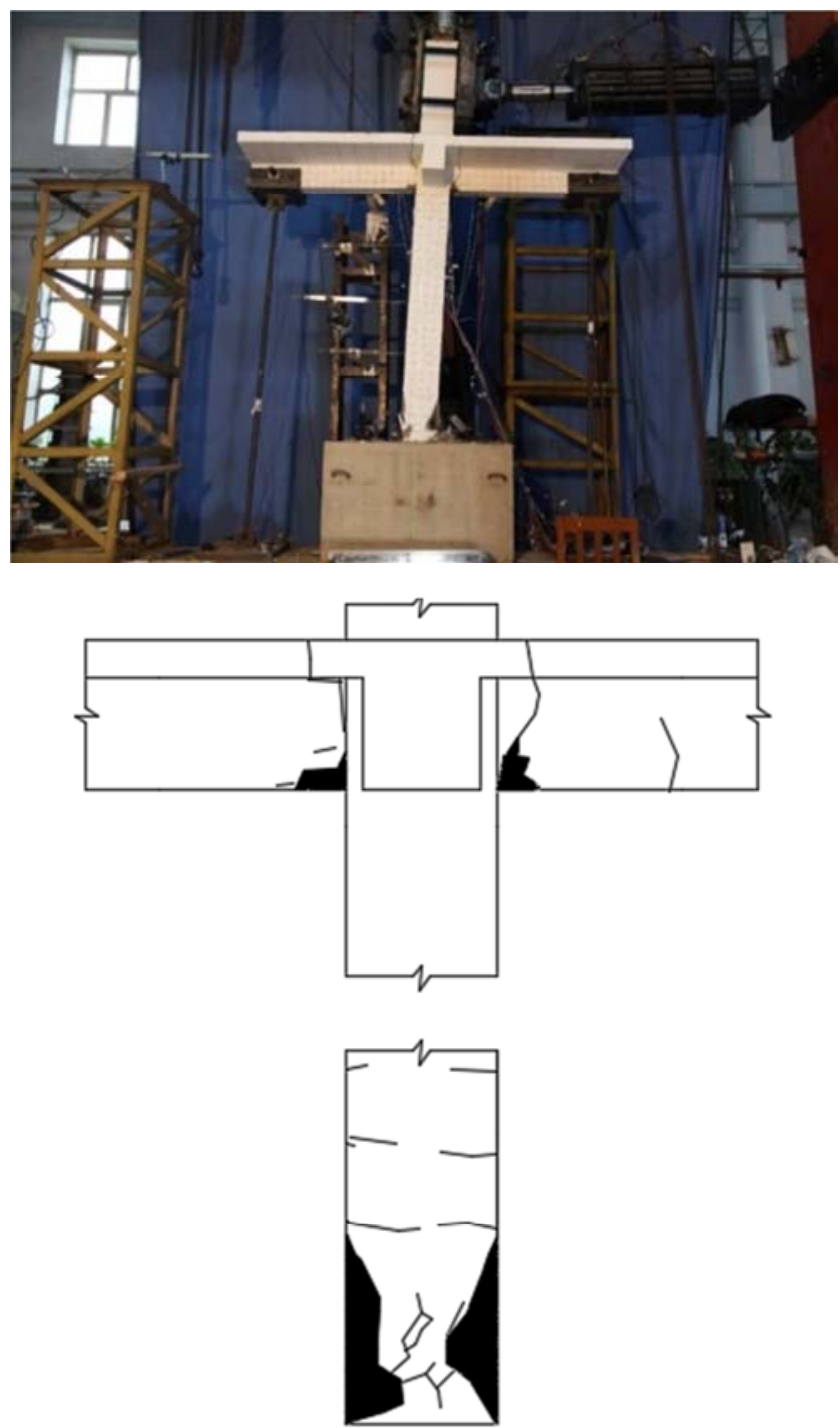

图3 试件最终裂缝图。

试件的荷载-位移滞回曲线以及骨架曲线如图4所示, 其中荷载为加载到柱顶端的水平作用力, 位移为加载点的 水平位移。试件最大承载力为 $36.5 \mathrm{kN}$, 最大承载力对应位 移角为 $1.32 \%$; 当承载力下降到最大承载力 $85 \%$ 时, 对应 位移角为 $2.1 \%$; 此试件整体达到了“强柱弱梁”、“强节点 弱构件”的结构设计目标。 


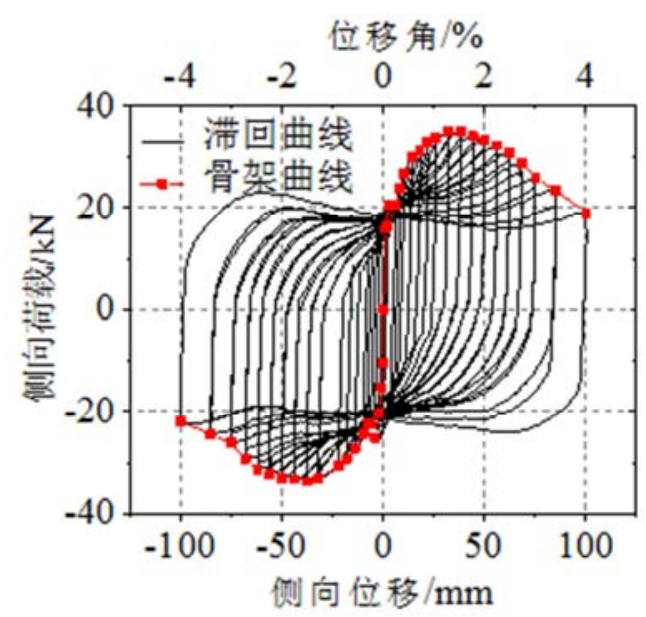

图4 滞回曲线与骨架曲线。

\section{2. 刚度退化}

结构水平侧向刚度变化是结构在水平往复荷载作用 下抗震性能的直观反映和重要影响因素, 故确定试件在水 平往复作用下的变化规律是研究其抗震性能及建立恢复 力模型的重要依据。刚度退化曲线如图5所示, 其刚度退 化均比较明显, 试件梁端在正弯矩作用下, 钢筋混凝土楼 板受压, 与梁共同作用抵抗压力; 然而在负弯矩作用下, 楼板混凝土抗拉能力较弱, 拉力基本由梁承担。试件在加 载过程中, 其割线刚度不断下降, 当承载力最大时, 割线 刚度下降为 $1.98 \mathrm{kN} / \mathrm{mm}$, 试件达到最大承载力之后, 其割 线刚度基本不变, 本试件刚度退化较快。

位移角 $/ \%$

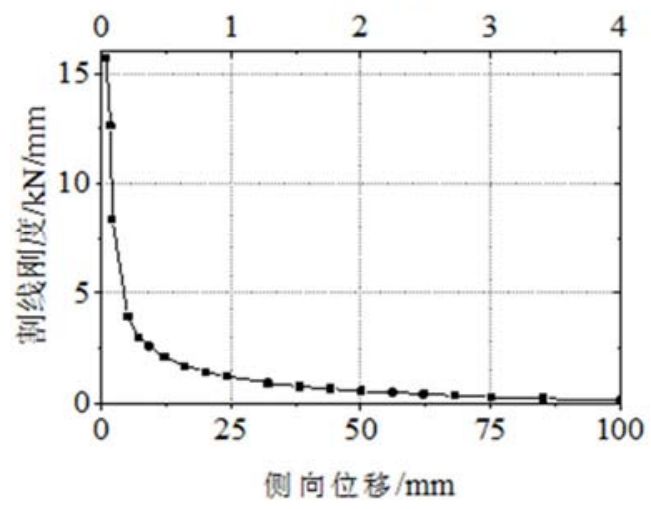

图5 刚度退化。

\section{3. 耗能能力}

在低周期反复荷载的作用下，基于试件的柱端荷载 -位移滞回曲线, 各滞回环面积即可度量构件在每个加 载循环内的耗能能力, 可对试件耗能能力进行综合评价。 试件的单圈滞回耗能如图6所示, 试件累积滞回耗能如 图7所示。随着加载位移的不断增大, 试件滞回耗能不 断增加、耗能能力不断提升, 当侧向位移达到 $100 \mathrm{~mm}$ 时, 单圈滞回耗能最大可达到 $7.89 \mathrm{kNm}$; 试件累积耗能可达 到 $38.6 \mathrm{kNm}$ 。

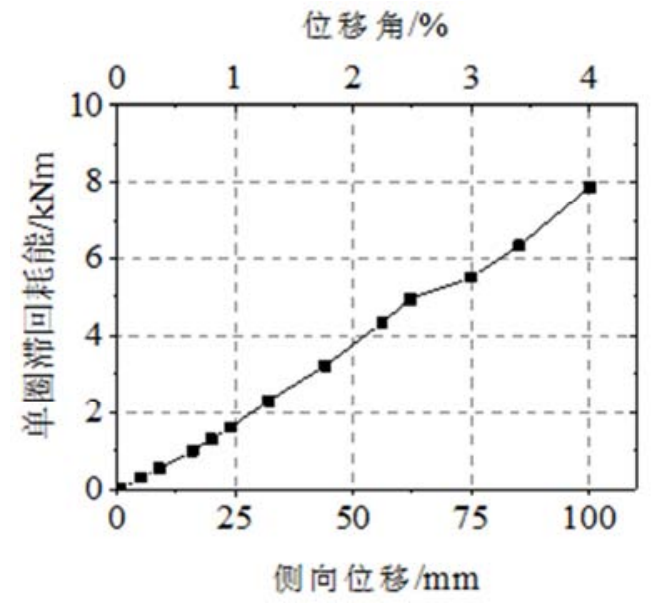

图6 单圈滞回耗能。

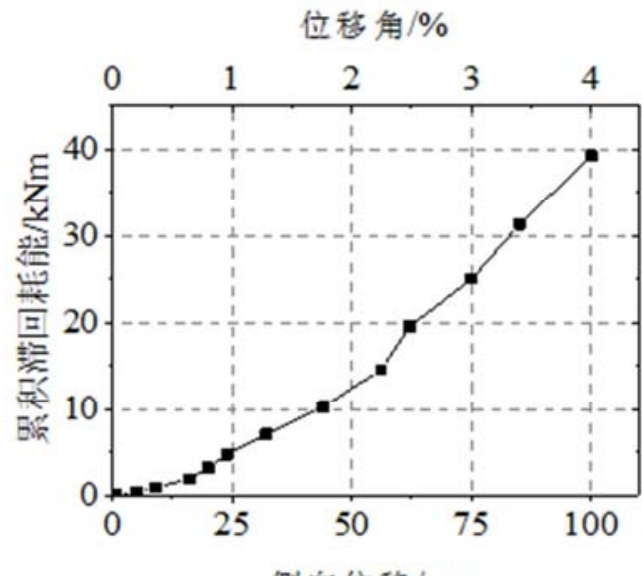

侧向位移 $/ \mathrm{mm}$

图7 累积滞回耗能。

等效粘滞阻尼比是按能量等效原则将实际阻尼耗能 换算, 根据Chopra[17]的研究成果, 它可以用来表示结构 耗能作用的大小。本试验试件等效粘滞阻尼比如图8所示。 当位移角在 $0.24 \%$ 之前, 试件等效粘滞阻尼比不断提高, 在达到 $0.24 \%$ 时结构减震耗能能力最好, 其等效粘滞阻尼 比为 $49 \%$; 其后不断下降, 下降至位移角为 $0.97 \%$ 时达到 最低 $37.4 \%$, 而后再次不断提高, 表明带板无填充墙的节 点耗能能力较好。

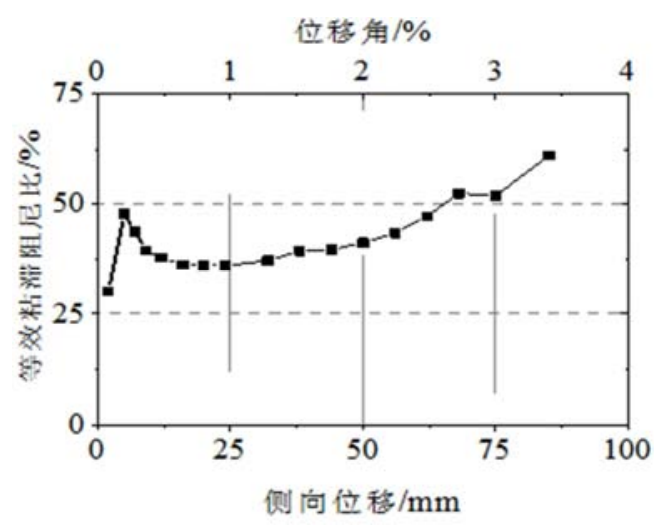

图8 等效粘滞阻尼比。 


\section{4. 结论}

通过对包含底层柱脚的有板梁柱中柱节点进行拟静 力往复加载试验和相关分析, 得到如下结论:

(1)根据现行抗震设计规范, 当柱端弯矩增大系数为 1.2 时, 包含底层柱脚的有板钢筋混凝土框架但无填充墙 的梁柱节点试验体在往复拟静力加载的作用下其刚度退 化较快, 耗能能力良好, 能够出现“强柱弱梁”、“强节点 弱构件”的破坏模式。

(2)试件最大承载力为 $36.5 \mathrm{kN}$, 最大承载力对应位移角 为 $1.32 \%$; 当承载力下降到最大承载力 $85 \%$ 时, 对应位移角 为 $2.1 \%$ 。本试件破坏顺序为底层柱脚-梁板-底层柱脚, 结 构在柱底产生了塑性铰, 梁柱节点中柱的位置始终未发生 破坏; 其破坏模式初期为抗弯破坏, 中后期产生弯剪破坏。

(3)按照现行规范设计的框架结构梁柱节点楼板对框 架梁的承载力和刚度增大的影响能够满足“强柱弱梁”的 结构设计概念, 在未来研究此课题时可着重考虑填充墙等 非结构构件、梁端超配筋以及梁柱可靠度的差异的影响。

\section{致谢}

本文为国家重点研发计划项目课题《城市工程强震 反应观测新型传感器及组网观测技术》

（2017YFC1500601）及其省级资助项目（GX18C005） 与国家自然科学基金面上项目 《基于贝叶斯估计的 $\mathrm{RC}$ 框架结构地震损伤概率识别方法改进与验证》

（51678541）的阶段性成果之一。

\section{参考文献}

[1] GB50011-2010建筑抗震设计规范[S]. 北京: 中国建筑工业 出版, 2016.

[2] 叶列平, 马千里, 繆志伟. 钢筋混凝土框架结构强柱弱梁 设计方法的研究 [J]. 工程力学,2010, 27(12): 102-113.

[3] 叶列平, 陆新征, 赵世春. 框架结构抗地震倒塌能力的研 究——汶川地震极震区几个框架结构震害案例分析 [J]. 建 筑结构学报, 2009, 30(6): 67-76.
[4] 蒋永生, 陈忠范, 周绪平, 鲁宗壳. 整浇梁板的框架节点 抗震研究 [J]. 建筑结构学报, 1994, 12(3): 11-16.

[5] Ehsani M R, Wight J K. Behavior of External Reinforced Concrete Beam to Column Connections Subjected to Earthquake Type Loading Univ. of Michigan, 1982, 6(1): 178-182.

[6] French C W, Moehle J P. Effect of floor slab on behavior of slab-beam-column connections [C]. Design of Beam-Column Joints for Seismic Resistance, SP-123,American Concrete Institute, Farmington Hills, Mich., 1991: 225-258.

[7] 唐九如. 钢筋混凝土框架节点抗震 $[\mathrm{M}]$. 南京: 东南大学出 版社, 1989.

[8] 苏佶智, 刘伯权, 马显东, 等. 钢筋混凝土框架结构层间 位移与构件变形关系研究 [J]. 建筑结构学报, 2020, 41(06): 152-163.

[9] 刘伯权, 苏佶智, 马显东, 等. Pseudo-static collapse experiment of multi-story multi-span reinforced concrete plane frames[J]. 土木工程学报, 2019, 052(008): 24-39.

[10] 王丽萍, 罗文文, 刘思危, 等. 考虑梁轴向约束效应的 RC 梁柱节点受力机理及抗震性能试验研究 $[\mathrm{J}]$. 工程力学, 2020, 37(02): 168-176+200.

[11] 初明进, 周育泷, 陆新征, 等. 钢筋混凝土单向梁板子结 构抗连续倒塌试验研究 [J]. 土木工程学报, 2016, 49(02): 38-47.

[12] 吴勇, 雷汲川, 杨红, 等. 板筋参与梁端负弯矩承载力问 题的探讨 $[\mathrm{J}]$. 重庆建筑大学学报, 2002, 24(3): 33-37.

[13] 管民生, 杜宏彪. 现浇楼板参与工作后框架结构的pushover 分析研究[J]. 地震工程与工程振动, 2005, 25(005):117-123.

[14] 邢国华, 周成, 吴涛, 等. 钢筋混凝土框架边节点现浇板 受拉有效翼缘宽度研究 [J]. 建筑结构学报, 2017,38(8): 65-73.

[15] 杨鹏. 楼板对 RC框架结构实现“强柱弱梁”目标影响研究 [D]. 长沙: 中南大学, 2013.

[16] JGJ/T101-2015建筑抗震试验方法规程[S]. 北京: 中国建筑 工业出版社, 2016.

[17] Chopra A K. Dynamics of Structures Theory and Applications to Earthquake Engineering[M]. Prentice Hall, Englewood Cliffs, New Jersey, 2001. 